NASA Technical Memorandum 104458

AIAA-91-1843

\title{
Review and Test of Chilldown Methods for Space-Based Cryogenic Tanks
}

David J. Chato and Rafael Sanabria Lewis Research Center

Cleveland, Ohio

Prepared for the

27th Joint Propulsion Conference

cosponsored by the AIAA, SAE, ASME, and ASEE

Sacramento, California, June 24-27, 1991 
REVIEW AND TEST OF CHILLDOWN METHODS

FOR SPACE-BASED CRYOGENIC TANKS

\author{
David J. Chato and Rafael Sanabria \\ National Aeronautics and Space Administration \\ Lewis Research Center \\ Cleveland, Ohio 44135
}

\begin{abstract}
This paper reviews the literature for tank chilldown methods applicable to cryogenic tankage in the zero gravity enviromment of earth orbit, selects one method for demonstration in ground based test, and then reports the results of that test. The method selected for investigation was the charge-hold-vent method which uses repeated injection of liquid slugs, followed by a hold to allow complete vaporization of the liquid and a vent of the tank to space vacuum, to cool tankage to the desired temperature. The test was conducted on a 175 cubic foot, 2219 aluminum walled tank weighing 329 pounds, which has been previously outfitted with spray systems to test nonvented fill technologies. To minimize hardware changes a simple control-by-pressure scheme was implemented to control injected liquid quantities. The tank cooled from $440 \mathrm{R}$ sufficiently in six charge-hold-vent cycles to allow a complete nonvented fill of the test tank. Liquid hydrogen consumed in the process is estimated at 32 pounds.
\end{abstract}




\section{INTRODUCTION}

The current interest in pressurized transfer of cryogenic fluids stems in part from NASA's plans for an ambitious human Space Exploration Initiative (CIAO) including manned voyages to the Moon and Mars. These activities will require enormous amounts of propellant stored as cryogenic liquids. The ability to efficiently transfer these cryogens between earth-to-orbit tanker vehicles, orbiting depots, and space transportation vehicles is required for mission success. Current transfer concepts include a tank chilldown stage to remove the majority of the thermal energy stored in the wall. This allows the wall energy to be removed, prior to the start of the fill process, rather than forcing it to be absorbed in the incoming liquid cryogen. Note: this paper focuses solely on the chilldown of tank walls, other chilldown processes such as line cooldown and engine prechilling, although also important will not be addressed.

chilldown of a cryogenic tank in a low-gravity enviroment has never been done. Although extensive data is available for ground-based tank chilldown of cryogenic tanks (e.g., Centaur upper stage, STS external tank), the techniques required to transfer cryogens in low gravity are quite different from those used terrestrially. During a normal-gravity tank chilldown, a vent on top of tank is kept open to vent the vapor generated during the chill process thereby maintaining a low tank pressure. If the normal-gravity technique is used onorbit, the uncertainty of liquid and vapor distributions in low gravity may result in the dumping of large amounts of liquid overboard.

\section{REVIEW OF THE LTTERATURE}

\section{General Transfer Systems}

Concepts for missions involving orbital fluid transfer can be found as early as the planning stages of the Apollo Program (ref. 1). One of the earliest detailed designs of an orbital fluid transfer system is found in reference 2. The reference 2 study proposed designs for $\mathrm{LO}_{2}$ and $\mathrm{LH}_{2}$ tankers based on an equilibrium analysis of the thermodynamics of the fill process, including vented and nonvented transfer methods. After an extensive survey of the existing literature, references 3 and 4 devised nonvented transfer schemes for the space tug and its successor, the orbital transfer vehicle (OTV), including transient analyses of the nonvented fill process. These analyses reconfirmed the difficulty of $\mathrm{LH}_{2}$ transfer described in the previous equilibrium analyses. As a solution to the problem of nonvented hydrogen transfer, a tank chilldown procedure was proposed to reduce the thermal energy which must be absorbed in the nonvented fill process. The NASA Lewis Research Center (LeRC) Cryogenic Fluid Technology office (CFTO) has refined and extended the analyses of references 3 and 4 (see ref. 5), as well as conducting ground testing of the nonvented fill concept. To determine the feasibility of nonvented fills on tanks representative of space flight hardware, a series of liquid hydrogen novent fill tests were developed for an existing $175 \mathrm{ft}^{3}$ lightweight liquid hydrogen tank (ref. 6). The no-vent fill testing provided an opportunity to conduct tank chilldown testing on hardware sufficiently close to flightweight to provide some meaningful data on the chilldown process. 
A early analysis of the tank chilldown process can be found in reference 7 . This study was undertaken to understand some transient problems encountered in the chilldown of Saturn and Titan propellant tanks on the launch pad, and is mostly concerned with normal gravity chilldown. Of most interest to the spacecraft designer is a series of tests with a 2 foot diameter plexiglass tank and liquid nitrogen which show sufficient force in the chilldown inflow process to geyser the incoming liquid to the tank vent. Reference 8 examined the problem of zero-gravity inflow, with several simulant fluids and a 4 inch diameter clear plastic tank, in the Lewis 2.2 second drop tower. The researchers of this study were unable to find an inlet configuration which did not wet the wall completely. Given the problems of liquid venting (Altas centaur 4 tumbled out of control due to an asymetric liquid vent during the low gravity coast portion of the mission (reference 9)), reference 3 proposed a chilldown procedure whereby the tank was charged with a small amount of liquid with the vent closed, the liquid is allowed to evaporate and approach thermal equilibrium, then vented as a gas. This cycle was repeated until the tank walls cooled sufficiently that a thermodynamic analysis of the tank indicated a nonvented fill could take place without further cooling. This process had the additional advantage that the cooling available in warming cold gas to ambient could also be extracted. This is particularly important with liquid hydrogen due its unique thermodynamic properties which make roughly six times the energy available in warming cold gas than that of vaporizing cold liquid. Reference 5 extended the analyses of reference 3 by analyzing optimum charge masses for each cycle as well as estimating an optimm "target" temperature for the start of the no-vent fill process. Also suggested in this paper was the use of multiple vent cycles to take advantage of the adiabatic cooling encountered in the venting process.

\section{PHYSICAL PROCESSES}

The baseline tank chilldown method under investigation is the chargehold-vent method. During the charge cycle, a small quantity of liquid cryogen is injected into the evacuated tank. Some type of spray nozzle is usually used to break the incoming liquid into droplets. Initially, the liquid flashes due to the low tank pressure, and then the remaining liquid droplets evaporate as they contact warm hydrogen vapor or the tank wall. During charge cycles, the heat transfer between the liquid and vapor is an important parameter in determining if any liquid droplets reach the wall.

During the hold period, the circulating flow pattern induced from the spray nozzles provides convective heat transfer from cold vapor to the tank wall. The primary mode of heat transfer during the hold is convection.

At the completion of the hold period, the pressure has risen considerably and the tank is ready to be vented. Since venting occurs as an isentropic blowdown, some additional cooling may be recovered by stage- wise venting. The key parameters of this method are (1) charge magnitude, (2) spray system selection, (3) mass flow rate, (4) hold duration, (5) acceleration enviromment, (6) desired tank wall temperature, and (7) maximum operating pressure. 
A ground-based test program may be able to validate the thermodynamic portions of the tank chilldown analyses and should yield fairly accurate modeling of on-orbit transient processes due to the similarity in the fluid motions. This is especially true for procedures such as tangential spray cooling.

Several tradeoffs exist. The efficient use of propellants requires that no liquid be vented overboard and that the cooling capacity of the cryogen be fully utilized. A slow tank chilldown process increases the time for fluid transfer and force the use of higher performance thermal protection; while overly complex hardware for tank chilldown would increase the weight of the spacecraft.

\section{TEST OBJECTIVES}

The objectives of the test were to demonstrate the feasibility of the charge hold vent chilldown process on a large flightweight tank and obtain an empirical understanding of the temperature and pressure transients involved. The tank was limited by qualification testing to a maximum operating pressure of 50 psia. The tank was limited to a maximum fill level of $94 \%$ due to requirements for some tank ullage to prevent the rapid tank pressure rise which occurs in a tank filled entirely with liquid. Due to the design of the transfer system, flow rate was determined by the selection of the supply dewar pressure. Concern about differential expansion between inlet systems led to recommending the simultaneous use of both the top spray and bottom spray systems from the nonvented fill tests. The previously mentioned follow-on nature of the test prevented the installation of the hardware necessary to implement a precise mass metering system. Instead a simpler control by pressure method was used. During the charge process a low transfer head was used so that as the tank pressure increased due to flashing liquid the flow would be automatically stopped after only a short inflow period. To prevent overpressurization of the tank during the hold period another pressure limit was established at 40 psia, whereby the tank would be vented to atmosphere once this pressure was reached. To study the effect of multiple vents and because of equipment limitations, a two stage vent procedure was established. First the tank was vented to atmosphere then following a five minute hold the tank was pumped down to near the hydrogen triple point pressure of 1.1 psia.

\section{FACILTTIES}

The tests were conducted at the LeRC Plum Brook Station Cryogenic Propellant Tank Facility (also known as K-Site). This facility combines a capability for safely handling liquid hydrogen with the vacuum required for multilayer insulation systems. The facility has a 25' diameter spherical vacuum chamber with a $20^{\prime}$ diameter entry door. Figure 1 is a simplified system schematic of the test facility as configured for the current test series. The chamber is rated for an $8 \times 10^{-7}$ torr vacuum under clean, dry, and empty conditions. The vacuum was maintained between $10^{-6}$ torr and $10^{-5}$ torr during the tests.

A shroud was installed inside the chamber to provide a uniform heat transfer enviromment. This shroud is cylindrical and measures 13' in diameter by $13^{\prime}$ long. During the tests it was warmed, by electric heater strips, to provide a uniform $530 \mathrm{R} \pm 1 \mathrm{R}$ radiant enviroment for the test tank. Mounted on the 
cryoshroud was a $2^{\prime} \times 5^{\prime}$ cylindrical coldguard. During testing, the coldguard is filled with liquid hydrogen boiling at near atmospheric conditions. All test tank lines, except the bypass line, pass through the coldguand and all instrumentation leads are thermally shorted to the coldguard. The coldguard minimizes the heat load to the test tank by absorbing the conduction heat transfer from the ambient enviroment along the test tank lines and instrumentation wires. The shroud and coldguard as well as the chamber entry are shown in figure 2 .

Liquid hydrogen for testing was supplied by a 13,000 gallon roadable dewar located outside the facility building. Prior to testing, the dewar was vented to nearly atmospheric pressure (roughly $1.6 \mathrm{psig)}$ and maintained there to cool the hydrogen to a uniform low saturation temperature throughout the dewar. During the test, the tank was pressurized to the desired transfer head by withdrawing a controlled quantity of liquid hydrogen, feeding it through a vaporization coil located under the dewar, and returning the resultant vapor back to the dewar. Due to the thermal lag between the raising of the tank pressure and the time for the cooled bulk liquid temperature to rise to the corresponding saturation temperature, a quantity of subcooled liquid hydrogen was available for injection.

The subcooled liquid hydrogen supply from the dewar flowed through a short section of vacuum jacketed flex hose into a vacun insulated pipe which carried the liquid hydrogen through the coldguard to the test tank valving.

Foam insulated pipe carried vent gases from the test tank out to the burnoffs for disposal. A new vent system was installed which enabled the test tank to be pulled down to hydrogen triple point pressures prior to the start of a test.

\section{EXPERTMENTAL HARDWARE}

\section{Test Tank}

The test tank selected is ellipsoidal with a 87 inch major diameter and a 1.2to-1 major-to-minor axis ratio. The two ends are joined by a short 1.5 inch cylindrical section. The tank is made of 2219 aluminum chemically milled to a nominal thickness' of 0.087 inches. Thicker sections exist where they were required for manufacturing (mainly weld lands). The tank has a 28.35 inch access flange on the top. The tank weighs 329.25 pounds, and the tank's volume is $175 \mathrm{ft}^{3}$. The tank was originally designed for a maximum operating pressure of 80 psia. Prior to the start of testing the tank was requalified by pneumatic test for a maximm operating pressure of $50 \mathrm{psia}$. The tank is covered with a blanket of 34 layers of multi-layer insulation (MII) made with double aluminized mylar and silk net spacers, and is supported by 12 fiberglass epoxy struts. The thermal performance of the tank is documented in reference 10. Figure 3 shows the tank installed in its support structure suspended over the cryoshroud.

\section{Spray Systems}

Current concepts (refs. 3 and 5) of in-space no-vent fill systems use one or more pressure atomizing spray nozzles to inject the liquid inflow as a stream 
of droplets through the ullage, thereby promoting condensation of the ullage gas on the droplet stream. Two spray systems are available. One spray system has a single spray nozzle at the bottom of the tank. This represents the worst case since it will flood soon after liquid begins to accumulate in the tank (at approximately 7\% liquid). The other spray system uses a cluster of 13 spray nozzles spraying from the top of the tank (13 spray nozzles were selected due to the availability of a commercial spray manifold with this configuration). These nozzles are located in a position such that the spray nozzles are not submerged until the tank is $92 \%$ full of liquid hydrogen.

The flow capacities of each system are sized, within the constraints of commercially available nozzle sizes, to have the same inflow rate for the same inlet pressure. Details of the nozzle sizing can be found in reference 10. The nozzles were sized to provide roughly $1000 \mathrm{lbm} / \mathrm{hr}$ hydrogen at a pressure drop of 10 psi. Figure 4 shows the two spray systems.

Test Tank Valving

A schematic of the tank valving and instrumentation inside the chamber is shown in Figure 5. Valving from the RPM tank test is used for controlling the fill-drain line (Valves 2513, and 2514) and the tank vent (valve 2515). Valve 2501 is teed into the fill-drain line between the coldguard and valve 2513. Valve 2501 controls flow to the spray systems. At the top of the tank, the line from 2501 splits into three lines. Two of these lines provide flow to the bottom and top spray, and each is conturolled by its own valve (2502 for the top spray, 2503 for the bottom jet). The third line bypasses flow out the facility vent. The bypass is used to cool the lines prior to the start of tests. Flow through the bypass is controlled by a valve outside the chamber.

\section{INSTRUMENTATION}

Instrumentation for lines external to the test tank are shown on the figure 5 schematic. Instrumentation internal to the tank and on the tank wall is shown in figure 6.

\section{Flowmeter}

Flow measurements are provided by a bidirectional venturi (preexistent from earlier tests) and two turbine flowmeters. The venturi is located in the inflow line inside the chamber and provides flow measurement for all inlet systems. The venturi was calibrated with water over a range of flow from 1 gpm to $15 \mathrm{gpm}$ (this is estimated to correspond to a range $3.76 \mathrm{gpm}$ to $56.4 \mathrm{gpm}$ of hydrogen). Two 0-1 psi delta pressure transducers provide pressure drop measurements for the bi-directional venturi. Delta pressure transducer accuracy is estimated at $\pm 3 / 4 \%$ full scale. Venturi resolution is limited by the accuracy of the 0-1 psid transducers. Estimated error in venturi reading is \pm 1 gpm water at the lowest flow rate and $\pm 0.1 \mathrm{gpm}$ water at the highest flow rate. Turbine flow meters are located at the inlet to each spray system; they provide a more accurate measure of flow than the venturi. The range of the turbine meters is from 0.6 to $60 \mathrm{gpm}$ with an accuracy of $\pm 1 / 2 \%$ of reading. 


\section{Pressure}

All pressure transducers are mounted outside the vacunm chamber and connected to the measurement taps by $1 / 4 "$ or $3 / 8$ " stainless steel tubes. Pressure transducers rated at 0-50 psia are located at the venturi inlet, upstream of the turbine flow meters and downstream of the spray system inlet valves. A 050 and a 0-100 psia transducer measure tank pressure from a tap in the capacitance probe. Installed accuracy is estimated at $\pm 1 / 2 \%$ full scale.

\section{Tank Internal Instrumentation}

Internal instrumentation consists of a capacitance level sensor and a rake of temperature and point level sensors. Stainless steel was selected as the material for internal instrument support due to its low thermal conductivity relative to other metals. The capacitance probe measures liquid fill heights between 2.9 and 66.7 inches from the tank bottom by measuring the change in capacitance of two concentric stainless steel tubes as the annular space between them fills with liquid hydrogen. Changes to the dielectric constant of hydrogen with pressure prevent the accuracy of the probe from being better than $\pm 1 \%$ full scale. The rake for other sensors is supported off the outer tube of the capacitance probe. The main body of the rake is a stainless steel sheet 1/8" thick by 1.5" wide and 63.84" long. Seventeen silicon diode temperature sensors are installed on the rake as shown in figure 11 . To further thermally isolate these sensors they are mounted on 1" $x 1.1$ " G10 micarta cards. Six of these are clustered on a single larger 2.18 " x 1.1" G10 card near the $85 \%$ fill level to measure thermal stratification. Accuracy of these diodes is $\pm 0.5 \mathrm{R}$ to $45 \mathrm{R}$ and $\pm 0.9 \mathrm{R}$ at higher temperatures.

\section{External Temperatures}

Silicon diode temperature sensors are used to measure temperature on the plumbing and tank wall: Two such sensors are located just downstream of the turbine flow meters, two are downstream of the spray system inlet valves, four are on the tank wall, four are on the tank fill/drain line, and two are on the tank lid. These diodes are slightly less accuracy than the internally mounted ones, accuracy is $\pm 0.9 \mathrm{R}$ below $180 \mathrm{R}$ and $1 \%$ of reading above that 180 R. A platinum resistance thermometer(PRT) inserted in a well located near the venturi is used to measure venturi liquid temperature with an accuracy of $\pm 0.2 \mathrm{R}$ over a range of 36 to $70 \mathrm{R}$. Facility systems and tank insulation are instrumented with a variety of PRTs, Type $\mathrm{E}$ and Type $\mathrm{K}$ thermocouples selected for predicted temperature and required accuracy.

\section{Data Collection}

Data is collected by the NASA LeRC ESCORT-D (see ref. 11 for more detail) mini-computer based system. Analog inputs from the facility are converted by a 12 bit analog-to-digital converter and updated once a second. ESCORT software converts the digital signal to engineering units and updates user designed displays on five CRT units located in the K-Site control building. Software routines are also used to convert temperature, pressure and volumetric flow readings into mass flow rates. Approximately 412 channels of 
data are recorded in the current test series. Data is recorded during the chilldown test run once every 15 seconds for the first 10 minutes of the charge cycle followed by once every minute for up to 4 hours. Data recording is started manually just prior to opening the inlet valves to start the charge cycle.

\section{TEST PROCEDURE}

Initial Conditions:

- Chamber pressure $<10^{-5}$ torr

- Cryoshroud controlled to $530^{\circ} \mathrm{R}$

- Coldguard filled and maintaining back pressure

- Tank near ambient temperature and at 1.1 psia filled with $\mathrm{GH}_{2}$

Test Procedure:

1. Set dewar pressure to desired transfer head and maintain after thermally soaking at atmospheric.

2. Flow through bypass until bypass temperature and venturi temperature are within $1^{\circ} \mathrm{R}$ and $<40^{\circ} \mathrm{R}$.

3. Initiate flow through both top spray and bottom jet.

4. Close top spray and bottom jet when flow drops to zero.

5. Hold until tank pressure reaches $45 \mathrm{psia}$, wall and internal gas temp reach close to equilibrium, or hold exceeds 2 hours.

6. Vent to atmospheric.

7.Hold for 5 minutes.

8. Pump Tank Down to 1.1 psia

9. Restart Data system

10. Repeat steps 1 to 10 until all tank temperatures are $<40^{\circ} \mathrm{R}$, or Tank is $94 \%$ full.

\section{TEST RESULTS}

The chilldown test was run on February 15, 1991 in between a series of nonvented fills. The test was started with the wall still slightly cooled from the previous nonvented fill at an average wall temperature of $440 \mathrm{R}$. The wall cooled sufficiently in six charge-hold-vent cycles that the seventh injection was capable of filling the tank to the $94 \%$ fill level cutoff. Time duration, mass injected, final tank pressure, and final average wall temperature for each stage of the chilldown process are tabulated in table 1. Mass injected for all cycles is calculated by averaging the mass flow reading over the injection period. At the one every 15 second sample rate only 3 to 4 readings of mass flow available were available so mass injection values are 
only approximate. Mass injected for cycles 1 and 2 are even more uncertain due to the presence of two phase flow in the venturi. Venturi flow rate and temperature are shown in figure 7 . Only the flow rate reading where the venturi is cooled to the $40 \mathrm{R}$ level can be considered valid. The initial two charge cycles were conducted with a 20 psia dewar pressure. In an effort to establish single phase flow in the inlet line the dewar pressure for the third cycle was set at 25 psia. This stabilized the flow at the venturi, but significant quantities of two phase flow were still encountered at the turbine meters. During cycle 4 the dewar pressure was increased to $30 \mathrm{psia}$. This did not completely eliminate the two-phase flow problem. However, to maintain a pressure margin between the dewar pressure and the 40 psia vent pressure, the dewar was left at 30 psia for the remainder of the test. Inlet and tank pressure histories are shown in figure 8. The sixth cycle was the only cycle in which the tank was vented due to reaching the 40 psia limit. Wall temperature histories are shown in figure 9. Wall cooling rates increase with each chill cycle, cycle 6 shows the greatest temperature drop. The span of internal temperature are shown in figure 10. Individual sensor readings have been omitted for the sake of clarity. Highest and Lowest sensor reading are retained to show the span of data. Individual reading follow the same trends as the bounding values. In general the upper sensors are the higher temperature readings and the lower sensors the lower temperatures. Drops in internal temperature can be seen after each charge and vent cycle. Tank liquid level is shown in figure 11. No significant liquid accumulation is seen until the nonvented fill.

\section{SUMMARY AND DISCUSSION}

This test series clearly demonstrates that the charge-hold-vent methodology is viable for cooling tanks. The test tank was cooled in six cycles to the point where a successful (to the $94 \%$ high level limit) nonvented fill was possible. cooling was fairly evenly distributed through the charge, hold and vent stages. On a cooling per unit time the hold stages were probably the least effective. Even so, a hold of only ten minutes or so was capable of extracting the majority of thermal energy available in the cold vapor which filled the tank. As the tank cooled the chilled process became increasingly effective. Figure 12 shows the distribution of temperature change between the cycles. During the first charge-hold-vent cycle the temperature change was less than $5 \%$ of the total temperature drop. In the sixth cycle more than $35 \%$ of the total temperature drop occurred. This effect is most likely due to the drop in specific heat of aluminum with decreasing temperature. The two phase flow problems encountered in the test seem attributable to the warming of the transfer lines when cryogen is not flowing, and are likely endemic to any process operating over as a broad a temperature range as the tank chilldown. The problems of two phase flow measurement make it unlikely that a precise mass metered system of tank chilldown can be implemented on operational systems, so future work will probably focus on control by pressure schemes. Total mass usage during the tank chilldown was estimated at about 32 pounds of hydrogen roughly $5 \%$ of the hydrogen needed to fill, so optimization of the chill process is unlikely to yield substantial dividend.

Areas of future work include an analysis of the test results and other data available to estimate empirical cooling rates for this test geometry. Tank 
chilldown data will continue to be collected on ad hoc basis as the Lewis Research center cryogenic transfer ground test program continues, although no further dedicated tests such as the one presented here are planned. Refinement of theoretical analyses of the chilldown process is also ongoing. Several small scale experiments are under development to further study the spray cooling processes of chilldown. As opportunities for on-orbit testing present themselves, tank chilldown experiments will be considered. Areas of open debate at Lewis consist of: the persistence of gaseous motion after cessation of spray; induced gaseous motion during the vent cycle; whether convective heat transfer is required for effective cooling during the hold stages; and what convection, if any, is likely to be encountered in zero gravity 
1. Bilstein, R.E., "Stages to Saturn," NASA SP-4206, 1980.

2. Morgan, L.L., et al., "Orbital Tanker Design Data Study," Lockheed Missiles and Space Co., IMSC-A748410, 1965.

3. Merino, F., Risberg, J.A., and Hill, M., "Orbital Refill of Propulsion Vehicle Tankage," NASA CR-159722, 1980.

4. Merino, F., Blatt, M.H., and Thies, N.C., "Filling of Orbital Fluid Management Systems," NASA CR-159404, 1978.

5. DeFelice, D.M. and Aydelott, J.C., "Thermodynamic Analysis and Subscale Modeling of Space-Based Orbit Transfer Vehicle Cryogenic Propellant Resupply," ATAA Paper 87-1764, June 1987 (NASA TM-89921).

6. Chato, D.J. "Analysis of the Nonvented Fill of a 4.96 Cubic Meter Lightweight Liquid Hydrogen Tank," ASME Paper 89-HT-10, August 1989 (NASA TM-102039).

7. Vernon, R. M., and Brogan, J. J., "A Study of Cryogenic Container Thermodynamics During Propellant Transfer", Volume II Final Engineering Report, Lockheed Missiles and Space Co., K-14-67-3, 1967

8. Labus, T. L., Aydelott J. C., and Andracchio C. R., "Effect of Baffles on Inflow Patterns in Spherical containers During Weightlessness," NASA TM X-2670, 1972.

9. Lacovic, R. F., et al, "Management of Cryogenic Propellants in a FullScale orbiting Space Vehicle," NASA TN D-4571, 1968.

10. DeWitt, R. L. and Boyle, R. J., "Thermal Performance of an Integrated Thermal Protection System for Long-Term Storage of Cryogenic Propellants In-Space", NASA TN D-8320, May 1977

11. Fronek, D. L., et. al., "A Distributed Data Acquisition System for Aeronautics Test Facilities", NASA TM 88961 
Table 1 Cycle History

\begin{tabular}{|c|c|c|c|c|c|}
\hline Stage & $\begin{array}{l}\text { Hydrogen } \\
\text { Mass } \\
\text { Injected } \\
\text { (lbm) }\end{array}$ & $\begin{array}{l}\text { Duration } \\
\text { (hrs) }\end{array}$ & $\begin{array}{l}\text { Final } \\
\text { Tank } \\
\text { Pressure } \\
\text { (psia) }\end{array}$ & $\begin{array}{l}\text { Final } \\
\text { Tank Wall } \\
\text { Temp. } \\
\text { (R) }\end{array}$ & $\begin{array}{l}\text { Change In } \\
\text { Termp. } \\
\text { (R) }\end{array}$ \\
\hline Start & & & 1.97 & 440.1 & \\
\hline Cycle 1 Charge & unknown ${ }^{*}$ & 0.0208 & 18.52 & 433.1 & 6.9 \\
\hline Hold & & 0.1375 & 20.56 & 428.7 & 4.4 \\
\hline Vent to Vacurm & & 0.0875 & 2.6 & 422.3 & 6.4 \\
\hline Cycle 2 Charge & $4.50^{\star}$ & 0.0167 & 18.01 & 412.4 & 10.0 \\
\hline Hold & & 0.1333 & 20.54 & 404.9 & 7.5 \\
\hline Vent to atmos. & & 0.075 & 14.23 & 402.3 & 2.6 \\
\hline Vent to Vacurm & & 0.0567 & 1.52 & 398.1 & 4.2 \\
\hline Cycle 3 Charge & 7.30 & 0.0125 & 23.39 & 385.7 & 12.4 \\
\hline Hold & & 0.1292 & 28.28 & 367.6 & 18.1 \\
\hline Vent to Atmos. & & 0.0875 & 14.22 & 361.8 & 5.7 \\
\hline Vent to Vacuum & & 0.0617 & 1.09 & 356.8 & 5.0 \\
\hline Cycle 4 Charge & 3.14 & 0.0125 & 30.21 & 339.1 & 17.7 \\
\hline Hold & & 0.1500 & 36.45 & 311.9 & 27.2 \\
\hline Vent to Atmos. & & 0.1042 & 14.21 & 302.6 & 9.3 \\
\hline Vent to Vacuum & & 0.0575 & 0.98 & 297.0 & 5.6 \\
\hline Cycle 5 Charge & 4.93 & 0.0125 & 31.59 & 276.3 & 20.7 \\
\hline Hold & & 0.1167 & 39.95 & 242.9 & 33.5 \\
\hline Vent to Atmos. & & 0.1041 & 14.26 & 229.8 & 13.1 \\
\hline Vent to Vacurm & & 0.0809 & 1.16 & 222.4 & 7.5 \\
\hline Cycle 6 Charge & 12.19 & 0.0208 & 30.4 & 172.5 & 49.9 \\
\hline Hold & & 0.025 & 39.96 & 136.4 & 36.0 \\
\hline Vent to Atmos. & & 0.1167 & 14.28 & 104.9 & 31.5 \\
\hline Vent to Vacuum & & 0.1325 & 1.12 & 76.7 & 28.2 \\
\hline Fill & 682.29 & 0.6 & 27.78 & 43.8 & 32.9 \\
\hline
\end{tabular}

"Two-phase Flow at Venturi Prevents Accurate Mass Flow Estimate 


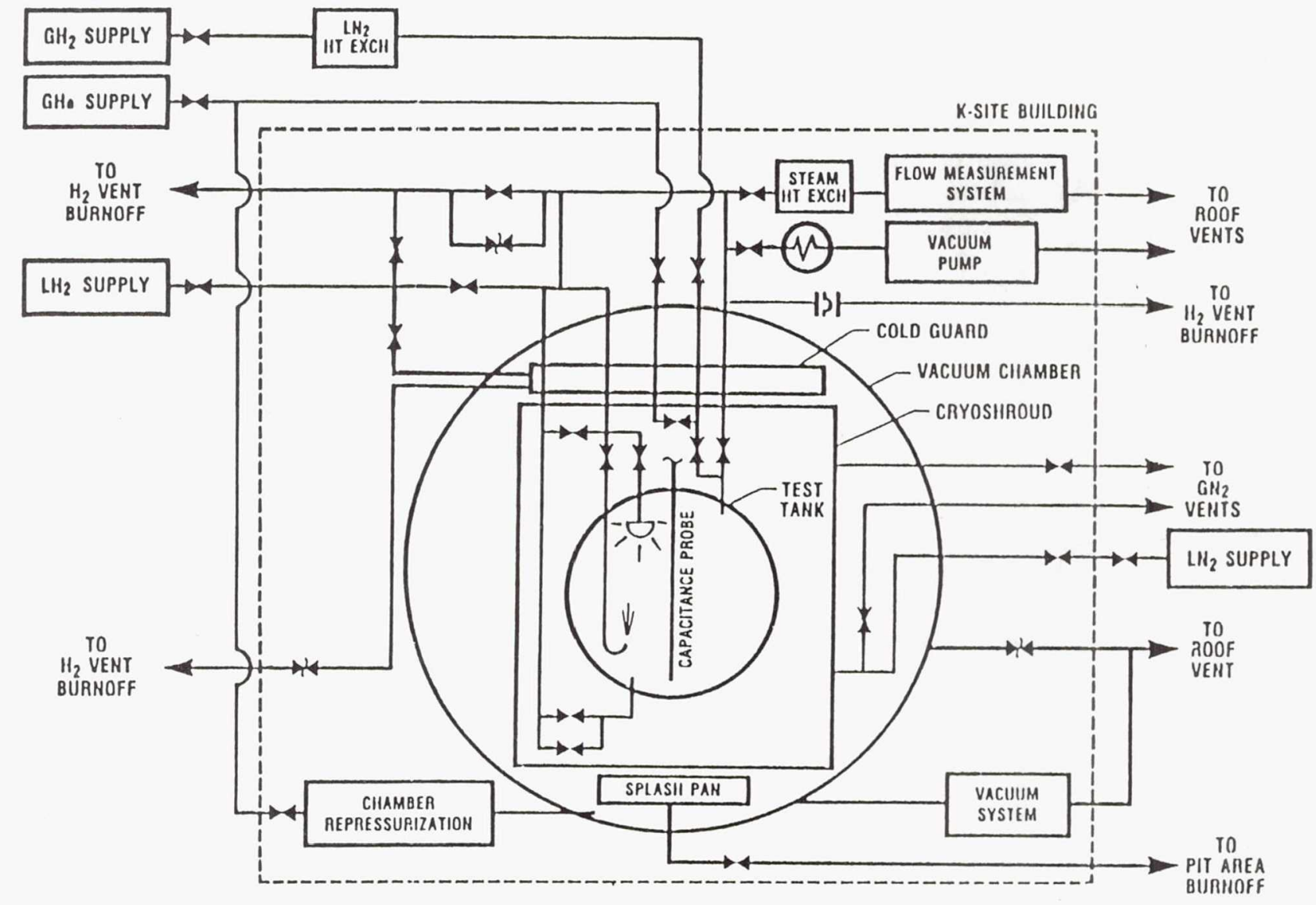

Figure 1.-K-site simplified facility schematic with research hardware. 


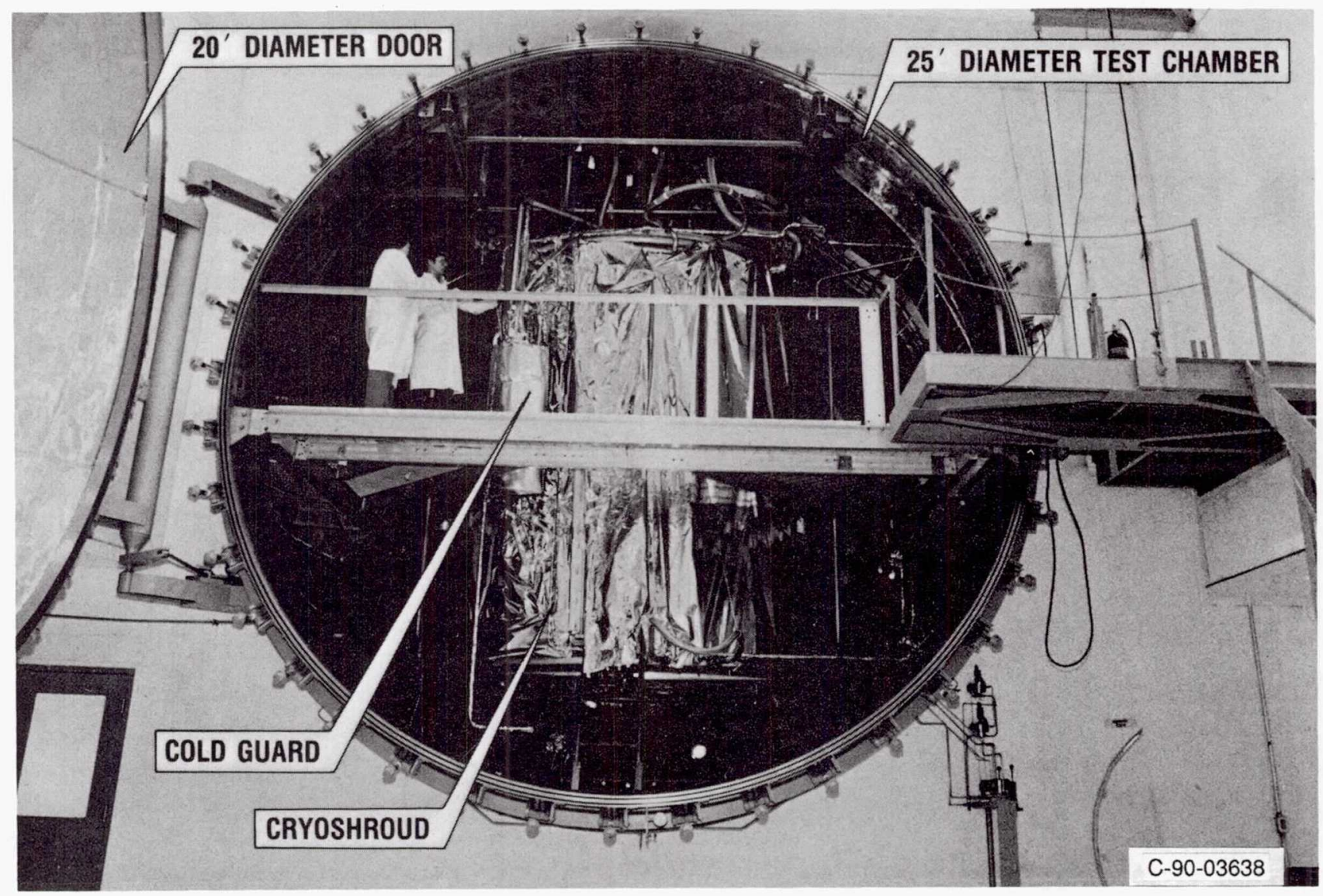

Figure 2.-View inside chamber with cryoshroud around $\mathrm{LH}_{2}$ test tank. 


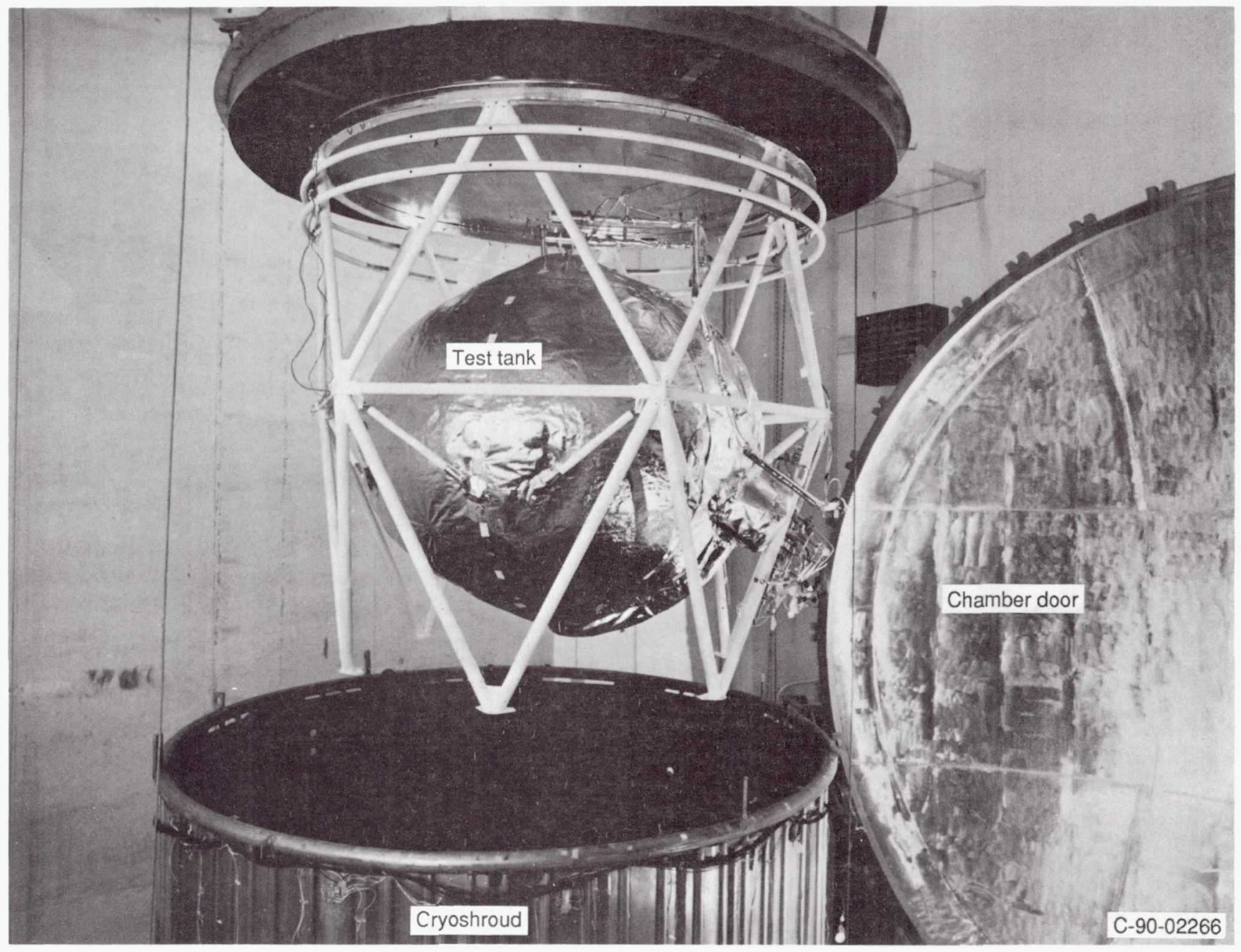

Figure 3.-Test tank suspended over cryoshroud. 


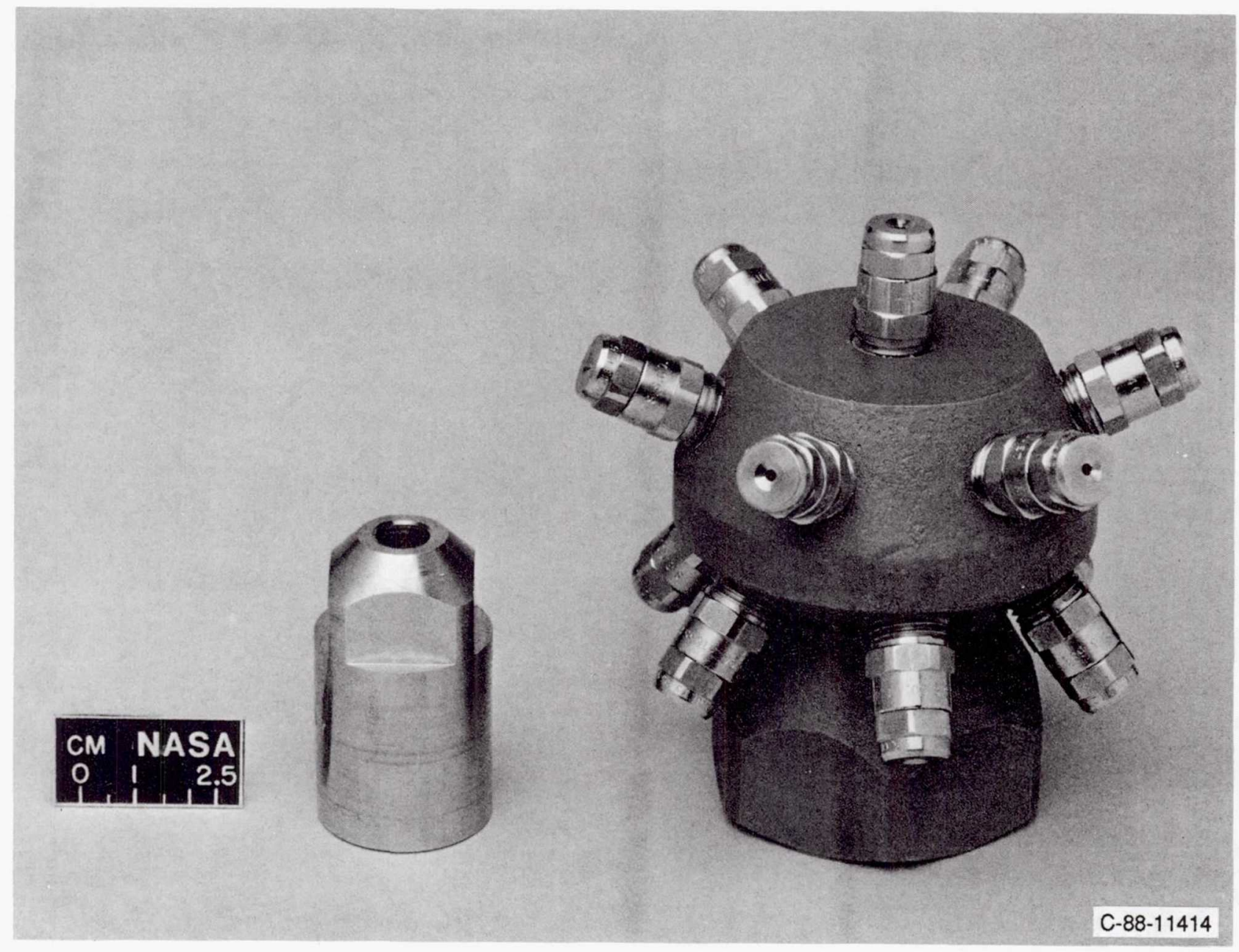

Figure 4.-Spray nozzles. 


\section{$\mathrm{P}, \mathrm{P}$ Pressure transducer}

$P, \Delta P \quad$ Delta pressure transducer

F, 8 Turbine flowmeter

$\mathrm{SD}, \mathrm{O}$ Silicon diode temperature sensor

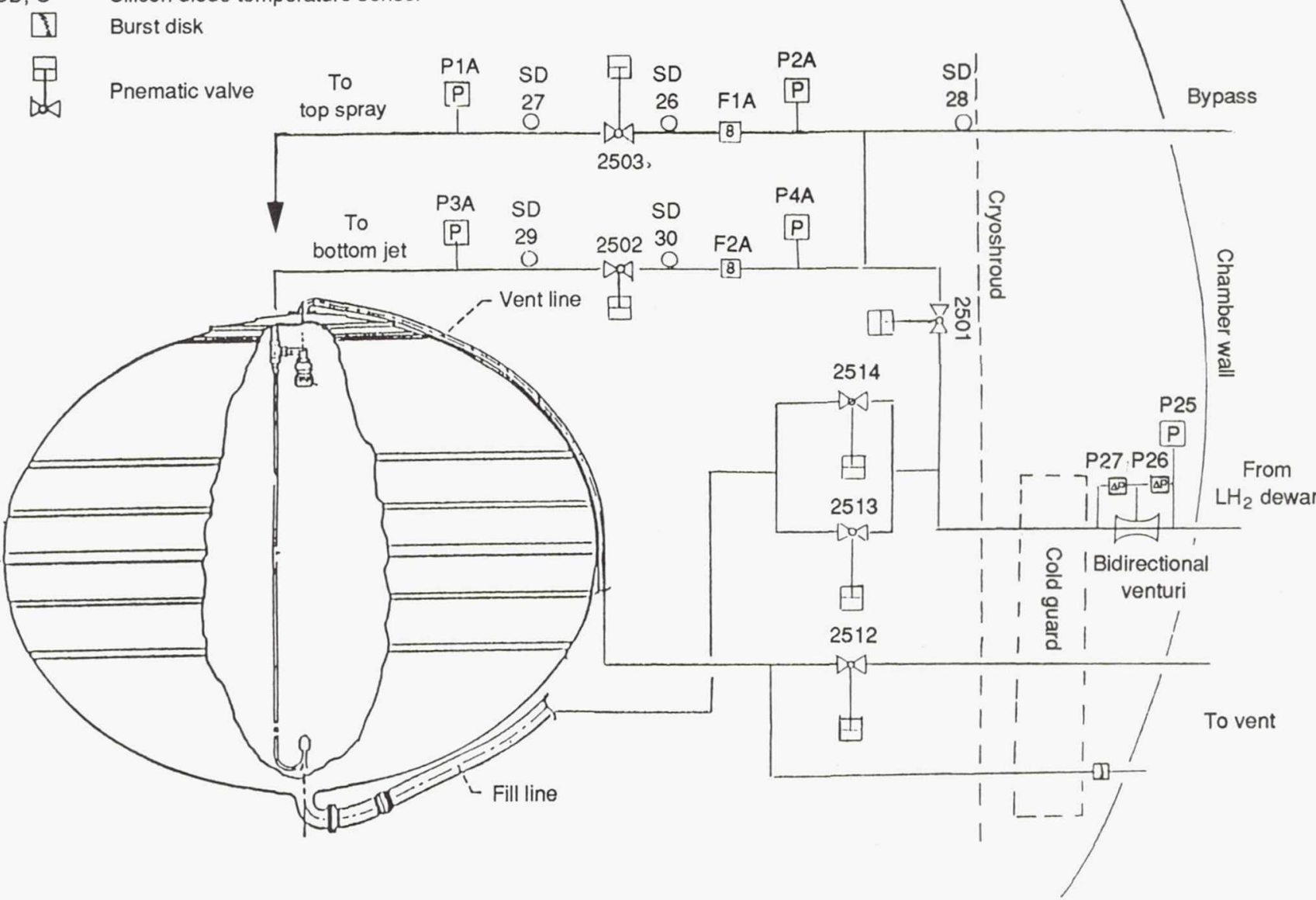

Figure 5.-Schematic of hydrogen lines in chamber. 


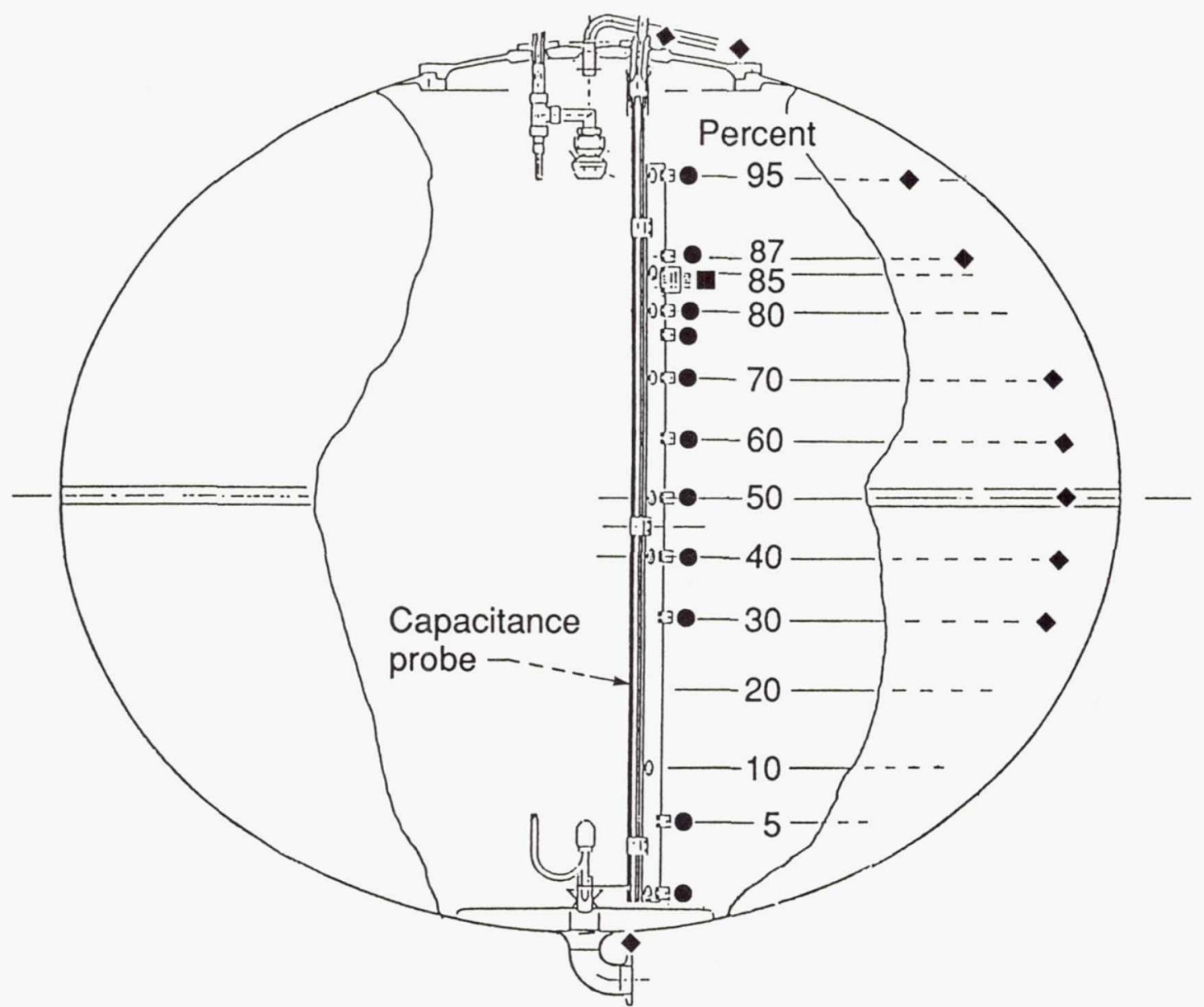

- Internal temperature sensors

- External wall temperature sensors

Close-spaced temperature sensors

near liquid-vapor interface

Figure 6.-Tank instrumentation. 
K-SITE PHASE IB CHILLDOWN

MASS FLOWRATES

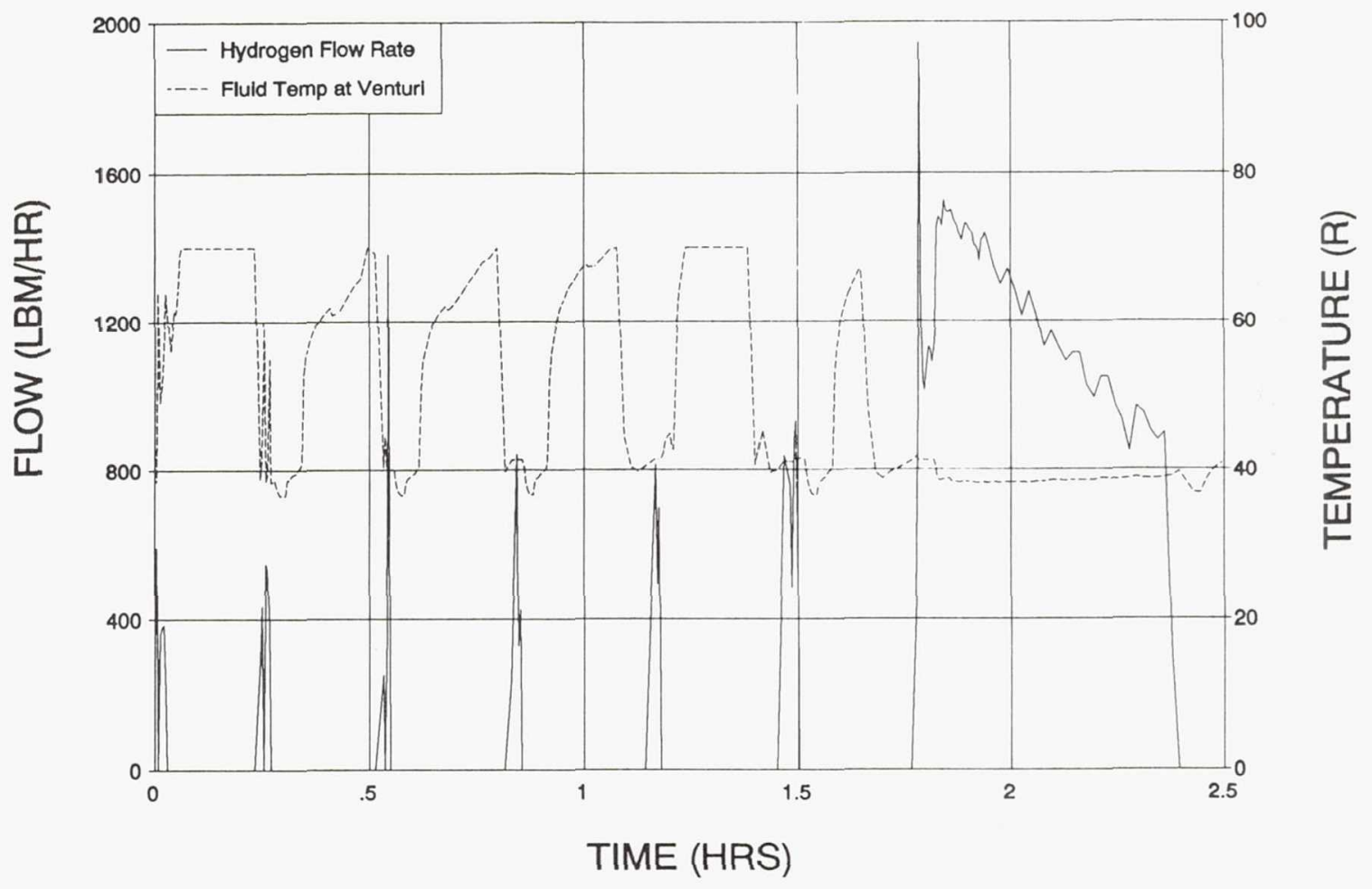

Figure 7.-Conditions at venturi. 


\section{K-SITE PHASE IB CHILLDOWN}

TANK PRESSURE

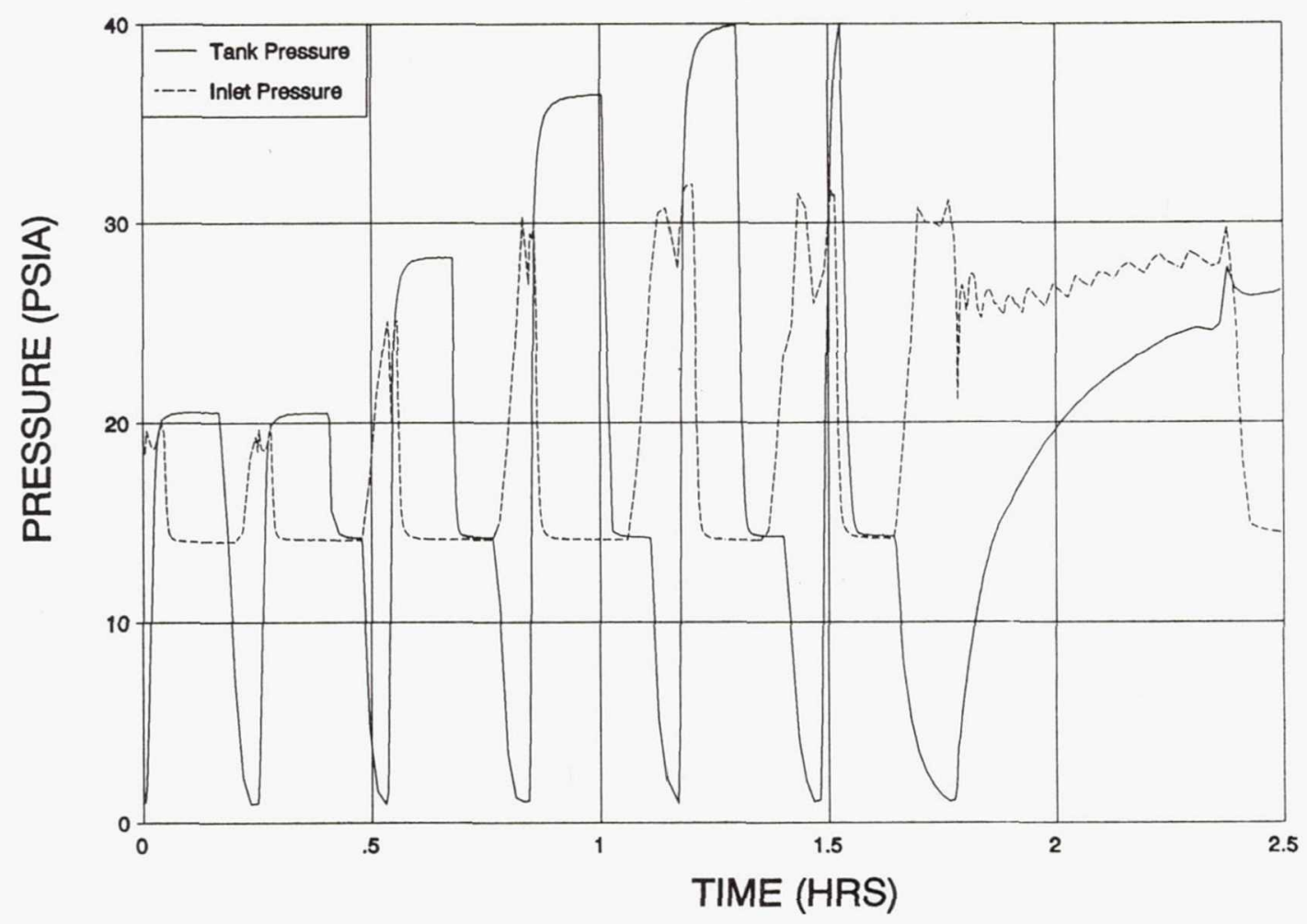

Figure 8.-Pressure history. 


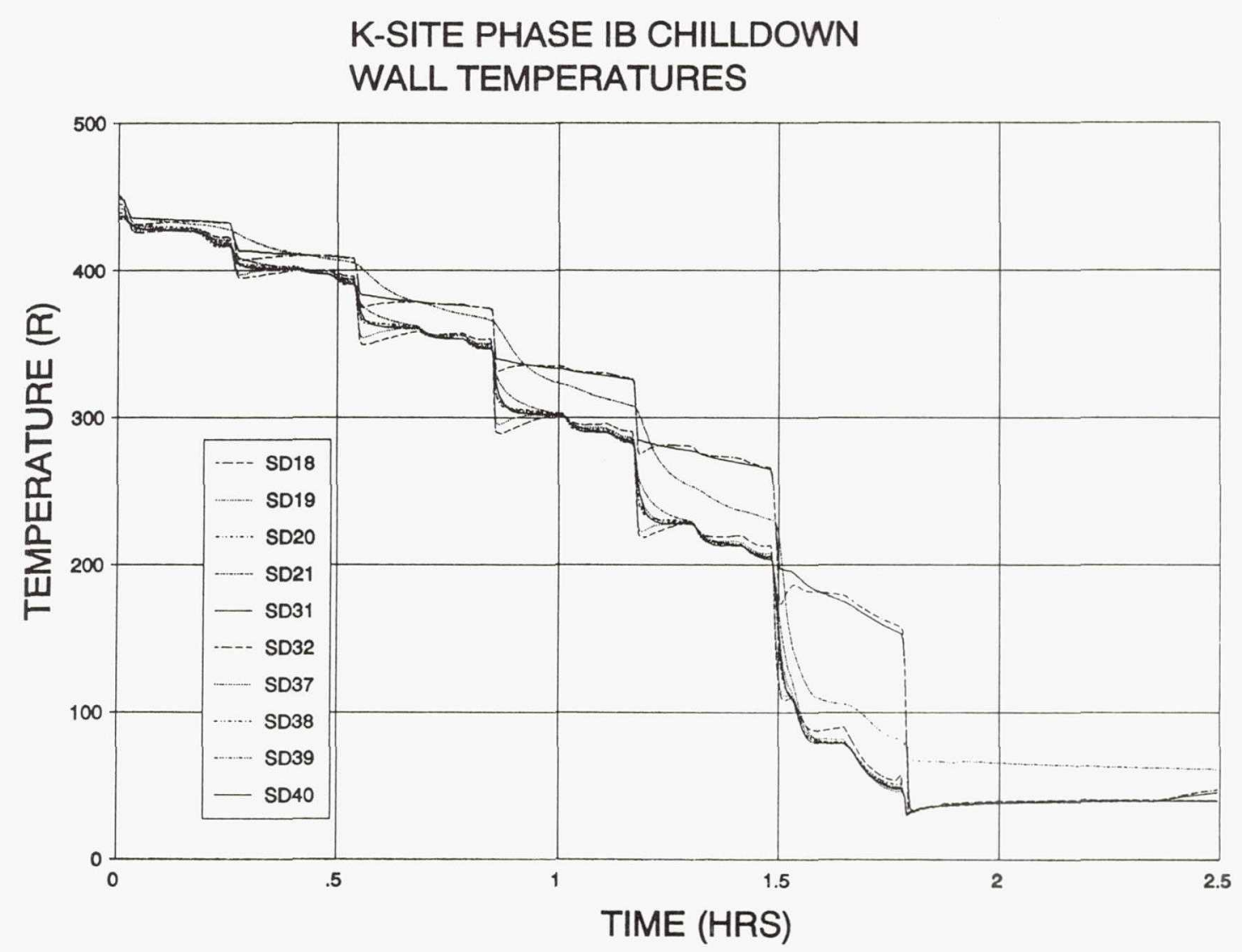

Figure 9.-Wall temperature. 


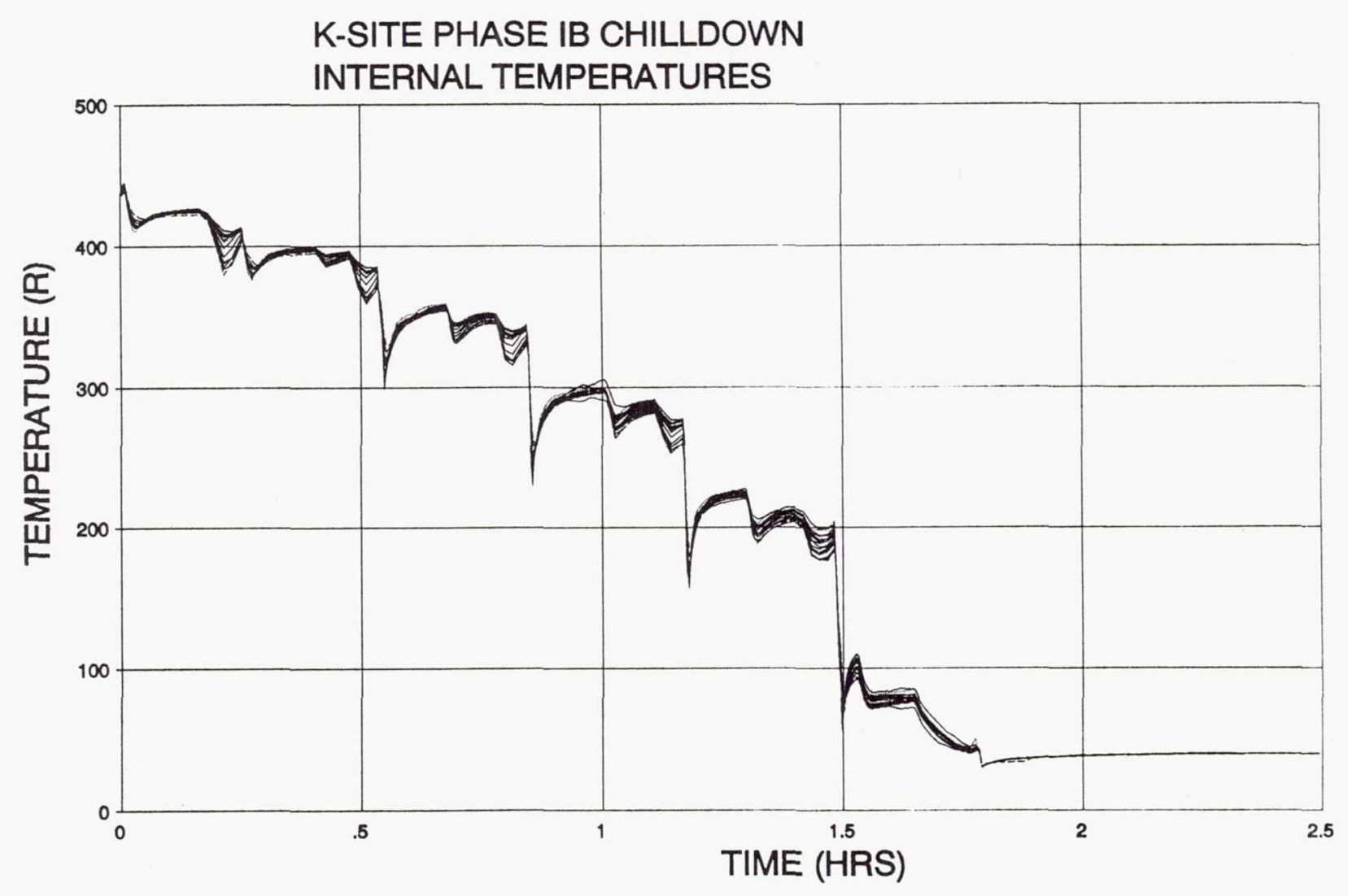

Figure 10.-Tank internal temperatures. 


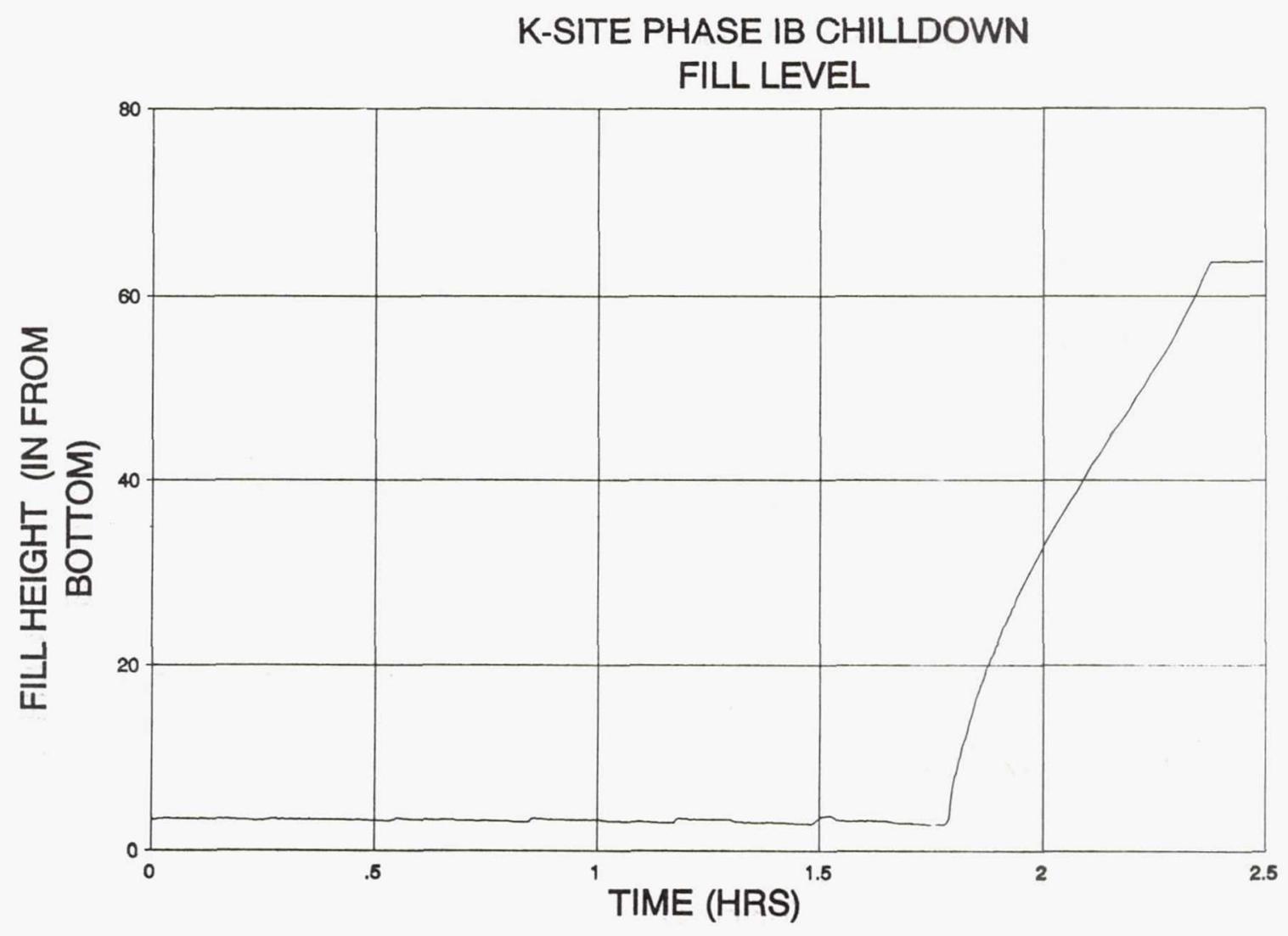

Figure 11.-Liquid level history 


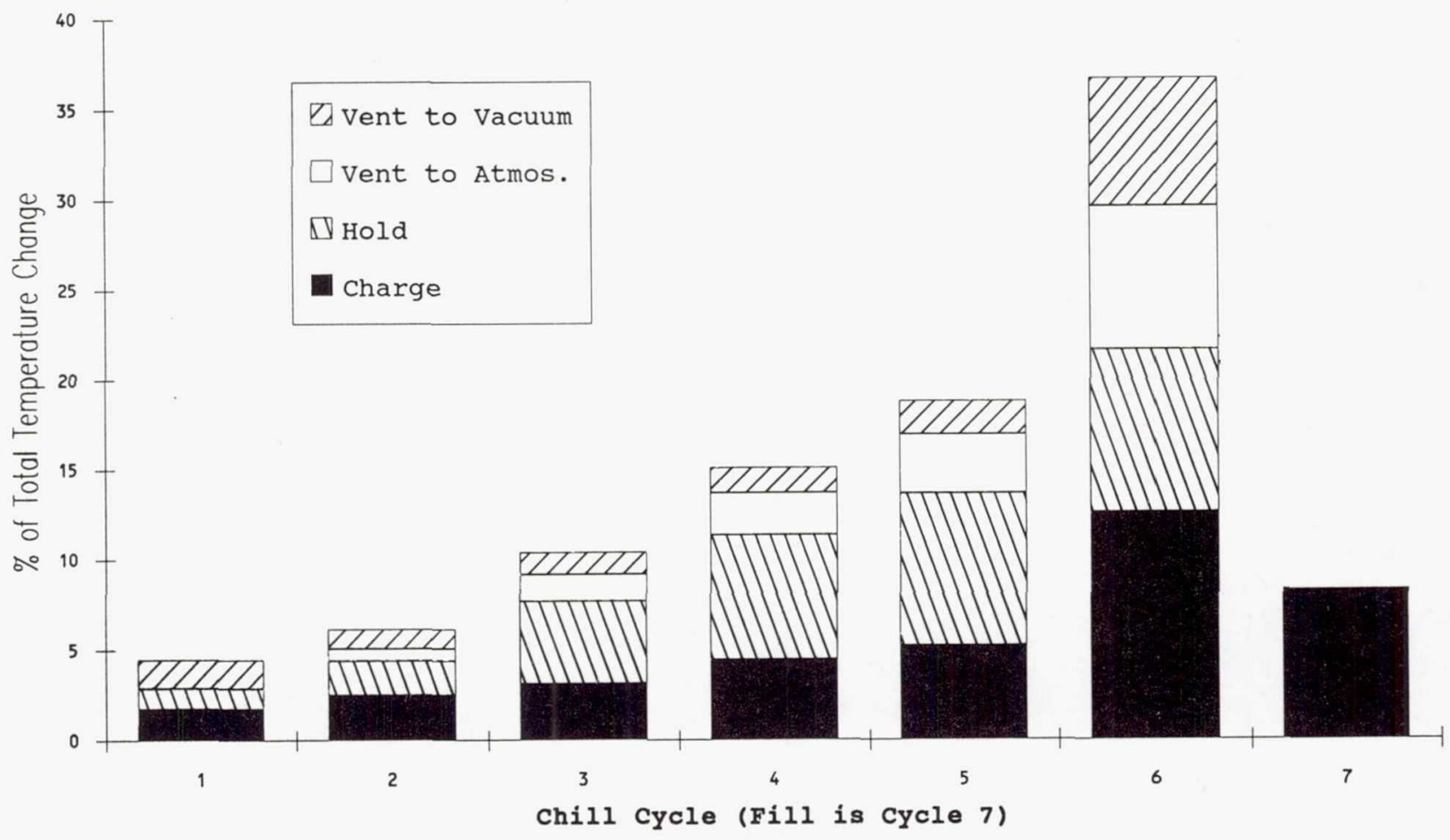

Figure 12.-Distribution of temperature change between charge cycles. 


\begin{tabular}{|c|c|c|c|}
\hline \multirow[t]{2}{*}{$\begin{array}{l}\text { 4. Title and Subtitle } \\
\text { Review and Test of Chilldowr }\end{array}$} & for Space-Based Cryogenic " & \multicolumn{2}{|l|}{ 5. Report Date } \\
\hline & & \multicolumn{2}{|c|}{ 6. Performing Organization Code } \\
\hline \multirow[t]{2}{*}{$\begin{array}{l}\text { 7. Author(s) } \\
\text { David J. Chato and Rafael San }\end{array}$} & & \multicolumn{2}{|c|}{$\begin{array}{l}\text { 8. Performing Organization Report No. } \\
\text { E -6299 }\end{array}$} \\
\hline & & \multicolumn{2}{|l|}{$\begin{array}{l}\text { 10. Work Unit No. } \\
506-48\end{array}$} \\
\hline \multicolumn{2}{|c|}{$\begin{array}{l}\text { 9. Performing Organization Name and Address } \\
\text { National Aeronautics and Space Administration } \\
\text { Lewis Research Center } \\
\text { Cleveland, Ohio } 44135-3191\end{array}$} & \multicolumn{2}{|c|}{ 11. Contract or Grant No. } \\
\hline \multirow{2}{*}{\multicolumn{2}{|c|}{$\begin{array}{l}\text { 12. Sponsoring Agency Name and Address } \\
\text { National Aeronautics and Space Administration } \\
\text { Washington, D.C. } 20546-0001\end{array}$}} & \multicolumn{2}{|c|}{$\begin{array}{l}\text { 13. Type of Report and Period Covered } \\
\text { Technical Memorandum }\end{array}$} \\
\hline & & \multicolumn{2}{|c|}{ 14. Sponsoring Agency Code } \\
\hline \multicolumn{4}{|c|}{$\begin{array}{l}\text { 15. Supplementary Notes } \\
\text { Prepared for the 27th Joint Propulsion Conference cosponsored by the AIAA, SAE, ASME, and ASEE, Sacramento, } \\
\text { California, June 24-27, 1991. Responsible person, David J. Chato, (216) 433-2845. }\end{array}$} \\
\hline \multicolumn{4}{|c|}{$\begin{array}{l}\text { 16. Abstract } \\
\text { This paper reviews the literature for tank chilldown methods applicable to cryogenic tankage in the zero gravity environ- } \\
\text { ment of earth orbit, selects one method for demonstration in ground based test, and then reports the results of that test. } \\
\text { The method selected for investigation was the charge-hold-vent method which uses repeated injection of liquid slugs, } \\
\text { followed by a hold to allow complete vaporization of the liquid and a vent of the tank to space vacuum, to cool tankage to } \\
\text { the desired temperature. The test was conducted on a } 175 \text { cubic foot, } 2219 \text { aluminum walled tank weighing } 329 \text { pounds, } \\
\text { which has been previously outfitted with spray systems to test nonvented fill technologies. To minimize hardware } \\
\text { changes a simple control-by-pressure scheme was implemented to control injected liquid quantities. The tank cooled } \\
\text { from } 440 \text { R sufficiently in six charge-hold-vent cycles to allow a complete nonvented fill of the test tank. Liquid hydro- } \\
\text { gen consumed in the process is estimated at } 32 \text { pounds. }\end{array}$} \\
\hline $\begin{array}{l}\text { 17. Key Words (Suggested by Author(s)) } \\
\text { Cryogenics } \\
\text { Liquid rocket propellants } \\
\text { Orbital servicing } \\
\text { Cooling }\end{array}$ & 18. Distr & $\begin{array}{l}\text { - Unlimited } \\
\text { gory } 34\end{array}$ & \\
\hline $\begin{array}{r}\text { 19. Security Classif. (of the report) } \\
\text { Unclassified }\end{array}$ & $\begin{array}{l}\text { 20. Security Classif. (of this page) } \\
\text { Unclassified }\end{array}$ & $\begin{array}{c}\text { 21. No. of pages } \\
26\end{array}$ & $\begin{array}{r}\text { 22. Price* } \\
\text { A03 }\end{array}$ \\
\hline
\end{tabular}

